\title{
From Sergeants and Soldiers to Chiral Conflict Effects in Helical Polymers by Acting on the Conformational Composition of the Comonomers
}

Felix Freire, Katherine Cobos, Rafael Rodríguez, Emilio Quiñoá, Ricardo Riguera

\section{Accepted Author Manuscript}

This is the peer reviewed version of the following article: Freire, F., Cobos, K., Rodríguez, R., Quiñoá, E. and Riguera, R. (2020), From Sergeants and Soldiers to Chiral Conflict Effects in Helical Polymers by Acting on the Conformational Composition of the Comonomers. Angew. Chem. Int. Ed.. Accepted Author Manuscript. doi:10.1002/anie.202009215, which has been published in final form at https://doi.org/10.1002/anie.202009215. This article may be used for non-commercial purposes in accordance with Wiley Terms and Conditions for Use of Self-Archived Versions

\section{How to cite:}

Freire, F., Cobos, K., Rodríguez, R., Quiñoá, E. and Riguera, R. (2020), From Sergeants and Soldiers to Chiral Conflict Effects in Helical Polymers by Acting on the Conformational Composition of the Comonomers. Angew. Chem. Int. Ed.. Accepted Author Manuscript. doi:10.1002/anie.202009215

\section{Copyright information:}

(C) 2020 Wiley-VCH GmbH. This article may be used for non-commercial purposes in accordance with Wiley Terms and Conditions for self-archiving 


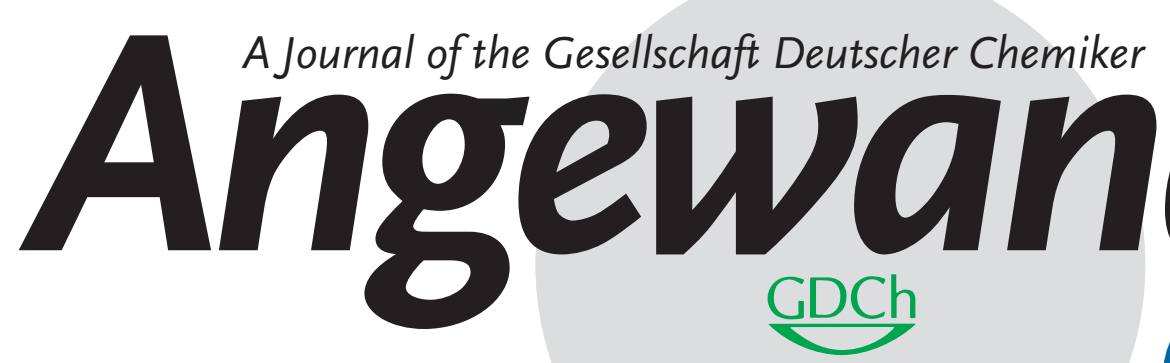

International Edition

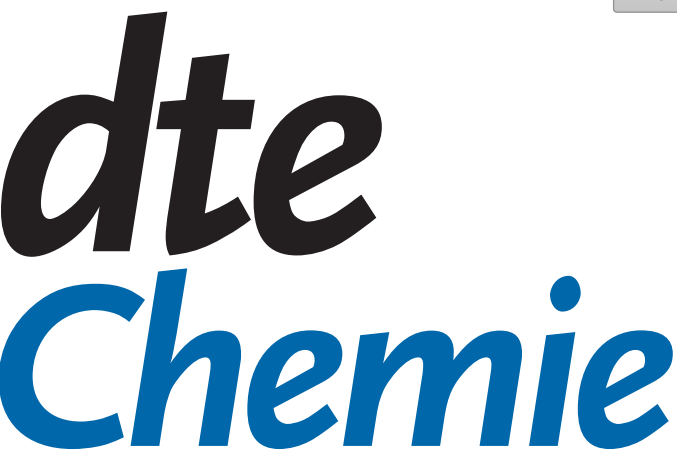

www.angewandte.org

\section{Accepted Article}

Title: From Sergeants and Soldiers to Chiral Conflict Effects in Helical Polymers by Acting on the Conformational Composition of the Comonomers

Authors: Felix Freire, Katherine Cobos, Rafael Rodríguez, Emilio Quiñoá, and Ricardo Riguera

This manuscript has been accepted after peer review and appears as an Accepted Article online prior to editing, proofing, and formal publication of the final Version of Record (VoR). This work is currently citable by using the Digital Object Identifier (DOI) given below. The VoR will be published online in Early View as soon as possible and may be different to this Accepted Article as a result of editing. Readers should obtain the VoR from the journal website shown below when it is published to ensure accuracy of information. The authors are responsible for the content of this Accepted Article.

To be cited as: Angew. Chem. Int. Ed. 10.1002/anie.202009215

Link to VoR: https://doi.org/10.1002/anie.202009215 


\title{
From Sergeants and Soldiers to Chiral Conflict Effects in Helical Polymers by Acting on the Conformational Composition of the Comonomers
}

\author{
Katherine Cobos, ${ }^{[[a]}$ Rafael Rodríguez, ${ }^{\ddagger[a]}$ Emilio Quiñoá, ${ }^{[a]}$ Ricardo Riguera, ${ }^{[a]}$ Félix Freire ${ }^{\star[a]}$ \\ [a] Dr. K. Cobos, Dr. R. Rodríguez, Prof. E. Quiñoá, Prof. R. Riguera, Prof. F. Freire \\ Centro Singular de investigación en Química Biolóxica e Materiais Moleculares (CiQUS) and Departamento de Química Orgánica, Universidade de \\ Santiago de Compostela, E-15782 Santiago de Compostela, Spain \\ E-mail: felix.freire@usc.es \\ Supporting information for this article is given via a link at the end of the document.
}

\begin{abstract}
Different communication mechanisms can be switched within a copolymer by acting on the conformational composition of the components and their chirality. Thus, a Sergeant and Soldiers effect is produced in two diastereomeric copolymer series - poly[(S)-1, - co$\left.(S)-\mathbf{2}_{(1-r)}\right]$ and poly $\left[(R)-\mathbf{1}_{r}-c o-(S)-\mathbf{2}_{(1-r)}\right]-$ due to the presence in chloroform of a preferred conformation in (S)-2, and a conformational equilibrium in $\mathbf{1}$, where a $P$ helix is induced independently of the absolute configuration of the Soldier. In THF, the presence of a conformational equilibrium at the pendants of the two components produces a reciprocal chiral enhancement effect by copolymerization of the two monomers, while in DMF, a third chiral to chiral communication switch is produced due to the presence of a single conformer at the pendant group of the two components. In such case, a Chiral Conflict or Chiral Accord effect is produced depending if the two components induce the same or the opposite helical sense.
\end{abstract}

\section{Introduction}

Dynamic helical polymers, such as poly(phenylacetylene)s (PPAs), are a fascinating family of long chain macromolecules whose helical scaffold (sense and/or elongation) can be modified by the action of different external stimuli. ${ }^{[1-10]}$ This phenomenon has been shown to allow the selective conversion of axially racemic polymers - composed by chiral or achiral monomersinto either of its two helical sense stereoisomers $(M$ or $P$ ) by the action of solvents - polarity and donor parameters-, metal ions, chiral molecules, temperature or $\mathrm{pH}^{\left[{ }^{[1-20]}\right.}$ On the other hand, if the starting polymer adopts a preferred $M$ or $P$ helix once is prepared, those stimuli can be used to produce structural modifications such as screw sense enhancement or helical inversion. ${ }^{[1-20]}$

An alternative way to induce a single-handed helical structure in an axially racemic polymer without altering the environmental conditions was described by Green and coworkers and denoted as Sergeants and Soldiers effect. ${ }^{[21-26]}$ They copolymerized an achiral monomer (Soldier, major component) with a small amount of a chiral monomer (Sergeant, minor component), and found that the $M$ or $P$ helical sense of the copolymer was determined exclusively by the $(R)$ - or $(S)$ - chirality of the Sergeant. ${ }^{[21-32]}$ In the Sergeants and Soldiers effect, the origin of the helical induction lies on the conformational restriction suffered by the Soldiers as a result of the preferred conformation adopted by the Sergeants. In addition, the combination of the Sergeants and Soldiers effect with the dynamic behavior of helical polymers makes possible the selective interconversion of a copolymer into its $M$ or $P$ helices by the action of external stimuli operating on the Sergeant moiety, which commands the Soldiers to adopt one helicity or the other. ${ }^{[30]}$ Thus, doping the achiral homopolymer with a small amount of an adequate chiral Sergeant is a very convenient way for the preparation of single-handed helical structures, with applications in fields such as sensing, ${ }^{[33-34]}$ chiral stationary phases ${ }^{[35-36]}$ or asymmetric synthesis ${ }^{[37-38]}$ among others.

A step forward in the study of communication mechanisms along polymeric chains arises from the copolymerization of two chiral monomers. The resulting copolymer allows us to explore not only which monomer rules the helix, but also how their absolute configurations affect the final helical structure. Our group has recently found that when a chiral monomer with no conformational preference - chiral Soldier - is copolymerized with another chiral monomer that exhibits a preferred conformational composition chiral Sergeant- (Figure 1), the resulting copolymer is governed by the classical Sergeants and Soldiers effect. ${ }^{[39-40]}$

In this way, this "chiral-to-chiral Sergeants and Soldiers effect" allows the preparation of four diastereomeric copolymers from chiral Sergeant (Sgt.)/chiral Soldier (Sold.) pairs - [poly-[(R/S)Sergeant-co-(R/S)-Soldier]-. In each copolymer, the helical sense is defined by the chirality of the Sergeant, while the chirality on the "surface" of the helix depends on the chirality of the Soldier exclusively. For instance, if the $(R)$-Sgt. commands a left-handed $(M)$-helix, both $(R)$ - and $(S)$-enantiomers of the Soldier adopt that (M)-helix although their intrinsic chiralities are the opposite (Figure 1b). However, if the enantiomeric form of the Sergeant (S)-Sgt.- is used, a $(P)$-helix is induced with either of the Soldier's two enantiomeric forms $-(R)$ - and $(S)$-Sold.- (Figure 1). ${ }^{[39]}$

In addition to the chiral-to-chiral Sergeants and Soldiers effect, our group has also described a new chiral communication phenomenon different from the classical Sergeants and Soldiers effect. $^{[38-41]}$ In the copolymers in which this phenomenon occurs, the two enantiomeric forms of the Sergeant activate the same conformation in the chiral Soldier and as a result, the helix is ruled by the absolute configuration of the Soldier and not by the enantiomeric form of the Sergeant. For instance, according to this mechanism, denoted as Chiral Coalition effect, [40] all the copolymers made by the same (S)-Sold. -in the example shown in Figure 2- show an $M$ helix regardless of the $(R)$ - or $(S)$-chirality of the Sergeant. To prepare the opposite $P$ sense in the helix of 
the copolymer, the enantiomeric Soldier has to be used, independently of the absolute configuration of the Sergeant. ${ }^{[40]}$

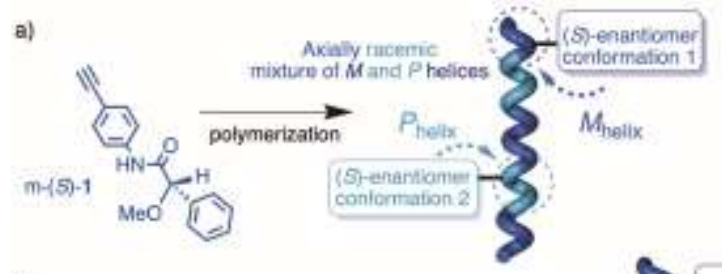

b)

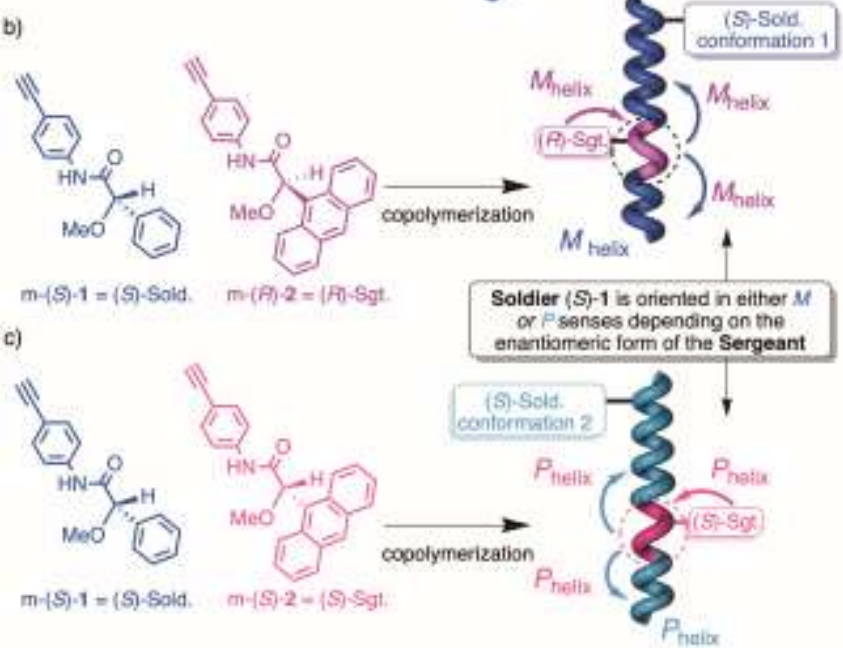

Figure 1. (a) Axially racemic polymer obtained from a chiral monomer $-m-(S)$ 1 - that is used as Soldier in the copolymers. $M$ and $P$ helices arise from two different conformations of the chiral monomer. (b) Conceptual representation of the chiral-to-chiral Sergeants and Soldiers effect using Sergeants with either $(R)$ - or (c) (S)-configurations. In the last two cases the same $(S)$-configuration of the Soldier is employed. Those same helical senses are obtained when the $(R)$-Soldier is employed with those same enantiomeric Sergeants. [Sgt.= Sergeant, Sold.= Soldier]

The combination of the classical Sergeants and Soldiers effect (chiral Sgt./achiral Sold.) with external stimuli has proven to be very useful to make copolymers with $P$ or $M$ senses. ${ }^{[30]}$ However, this helix inversion process does not work well in copolymers where the two comonomers are chiral because once an external stimulus is added, the chiral-to-chiral communication is disrupted, decreasing the screw sense preference in the copolymer. ${ }^{[39]}$ As a consequence, it is not possible to obtain the two $P$ and $M$ helical senses from the same copolymer. To that end and to date, it is necessary to prepare two different copolymers with opposite configurations at the Sergeant.

Herein, we will show that different chiral-to-chiral communication mechanisms can be activated within a chiral copolymer chain by acting on the conformational composition of the co-monomer used as chiral Sgt. Moreover, the chiral enhancement effect induced in the copolymer will also depend on the relative absolute configurations between the Sergeant and the Soldier. As a result, for a single chiral Sgt./chiral Sold. pair, it is possible to activate a complete set of communication mechanisms: Chiral-to-Chiral Sergeants and Soldiers effect, Chiral Coalition, Chiral Conflict, Chiral Accord and also a synergistic chiral enhancement effect.

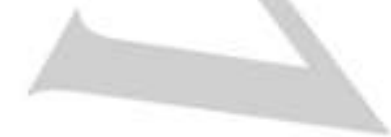

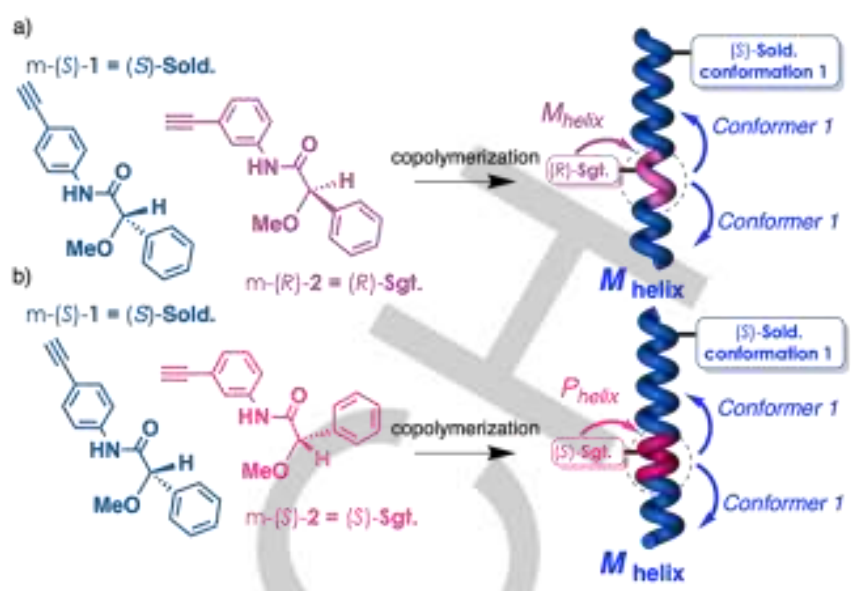

Figure 2. (a) Conceptual representation of the Chiral Coalition effect using Sergeants with either $(R)$ - or (b) $(S)$-configurations. The same $(S)$-configuration of the Soldier is employed in both cases and $(M)$-helices are obtained. $(P)$ helical senses arise when the $(R)$-Soldier is employed with those same enantiomeric Sergeants. [Sgt.= Sergeant, Sold.= Soldier].

\section{Results and Discussion}

To perform these studies, the 4-ethynylanilides of $(R)$ - or $(S)$ - $\alpha$ methoxy- $\alpha$-phenylacetic acid (MPA) were chosen as chiral Soldiers [monomers $(R)$ - or $(S)$-1] (Figure 3), ${ }^{[42-47]}$ while the 4ethynylanilide of the (S)-mandelic acid (MA) was selected as chiral Sergeant [monomer (S)-2]. ${ }^{[48]}$ The difference between these two monomers is one substituent at the chiral carbon. Thus, while monomer $\mathbf{1}$ bears a methoxy group, monomer 2 possess a hydroxyl group (Figure 3a and 3b). However, this only apparently small difference between the two monomers produces a large difference in the dynamic behavior of the corresponding monomers and homopolymers. ${ }^{[48]}$

Monomer $1[(R)$ - or $(S)$-Sold.] is known to have two main conformations at the $(\mathrm{O}=) \mathrm{C}-\mathrm{C}(-\mathrm{O})$ bond in low polarity solvents: one with an antiperiplanar (ap) orientation and the other with a synperiplanar ( $s p$ ) orientation between the carbonyl and methoxy groups, in a ratio close to $1: 1$ (Figure 3a). ${ }^{[46]}$

This conformational equilibrium is also present in their corresponding homopolymers [poly-(R)-1 and poly-(S)-1], producing in each of them equal amounts of cis-cisoidal $P$ and $M$ helices. As a result, axially racemic and optically inactive (null CD) materials are generated despite the configuration of their stereogenic carbon centers ${ }^{[46]}$ (Figure $3 c$ ). On the other hand, in polar solvents, the equilibrium is shifted towards a $s p$ conformation which induces a screw sense excess towards an $M$ helix for poly- $(R)-\mathbf{1}$ and a $P$ helix for poly-(S)-1. These polymers can be transformed into chiral materials by the action of external stimuli such as monovalent or divalent metal ions, which selectively induce $P$ or $M$ helices in poly-1 by fixing either ap (monovalent metal ions) or $s p$ (divalent ones) conformations in the pendants. ${ }^{[46]}$

On the other hand, monomer $2[(R)$ - or $(S)$-Sgt.] has a major ap conformation at the $(\mathrm{O}=) \mathrm{C}-\mathrm{C}(-\mathrm{O})$ bond (Figure $3 \mathrm{~b})$, which can be shifted to $s p$ by adding stimuli such as $\mathrm{Ba}\left(\mathrm{ClO}_{4}\right)_{2} \cdot{ }^{[48]}$ The homopolymer - poly- $(R)-2$ - has a cis-cisoidal structure with a preferred $M$ helical sense in low polarity solvents - ap pendant-, while a $P$ helicity is induced in polar solvents due to the presence of major $s p$ conformations at the pendants (Figure $3 \mathrm{~d}$ ). In poly- 
(S)-2, and due to its enantiomeric relationship with poly-(R)-2, a $P$ helix is induced in low polarity solvents while an $M$ helix appears in polar solvents (Figure $3 d$ ).

Similar to what happens with the corresponding monomers, a conformational switch can be produced in the pendant groups by adding metal ions such as $\mathrm{Li}^{+}$or $\mathrm{Ba}^{2+}$, which generate either a chiral amplification or a helix inversion in poly-2.

These two monomers $\mathbf{1}$ and $\mathbf{2}$ meet all the necessary requirements to show an effective chiral communication mechanism along a copolymer chain as found in our previous studies:[37,39-41] 1) similar scaffolds for the parent homopolymers -i.e., cis-cisoidal-; 2) conformational flexibility at the Soldier highly dynamic poly-1-; 3) the presence of a preferred conformation at the Sergeant —screw sense excess in poly-2-; 4) the same functional group used as connector between the pendant and the backbone in both Sergeant and Soldier -i.e., anilide- . a)

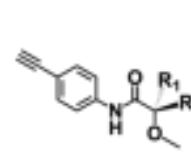

(R)-1, R $R_{1}=H \quad R_{2}=P h$ (S) $-1, R_{1}=P h \quad R_{2}=H$

b)

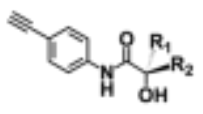

c)
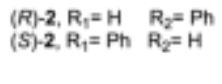

\section{chiral Soldier $=2$ consormations in equilbrium}

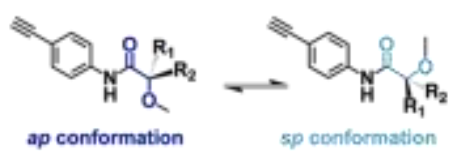

chiral Sergeant $=1$ major conformation

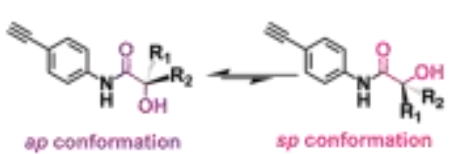

ap conformation
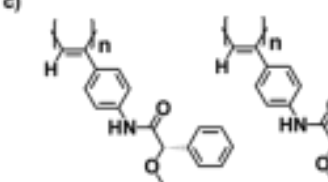

$t=n$
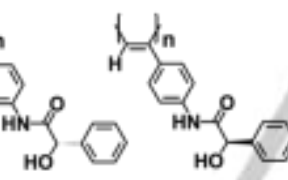

Poly-(S)-1

Poly-(R)-1

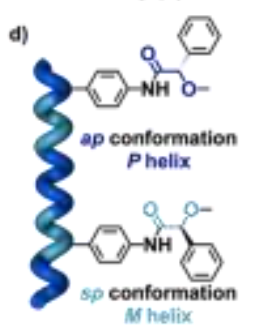
Poly-(S)-1
axially racomic

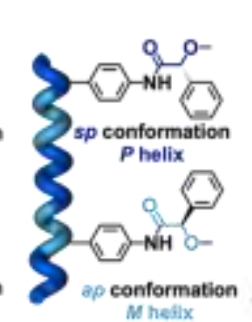

$y-(S)-2$

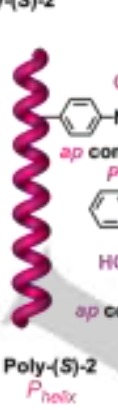

Poly-\{R\}-2
Figure 3. Figure 3. Structure and conformational equilibrium between ap and $s p$ conformations for monomers (a) $(R)$ - and $(S)$-1 and (b) $(R)$ - and $(S)-2$. (c) Structure of poly- $(R)-$ and poly-(S)-1 and 2. (d) Schematic illustration of the helical structures adopted by the enantiomeric forms of poly-1 and poly-2 in low polarity solvents.

Next, copolymer series poly[(S)-1, co- $\left.(S)-\mathbf{2}_{(1-r)}\right]$ and poly $\left[(R)-\mathbf{1}_{r}-\mathrm{co}-\right.$ $\left.(S)-\mathbf{2}_{(1-n]}\right](r=0.9-0.1)$ were prepared by polymerizing mixtures of the chiral Sergeant $[(S)-2]$ and the chiral Soldiers $[(S)-1$ and $(R)$ $1]$ in different ratios with $\left[(\mathrm{Rh}(\mathrm{nbd}) \mathrm{Cl})_{2}\right]($ Figure 4$)$. The other two diastereomeric copolymer series - poly $\left[(R)-\mathbf{1}_{\text {rco- }}(R)-\mathbf{2}_{(1-n)}\right]$ and poly $\left[(S)-1_{r}-c o-(R)-2_{(1-n)} \quad(r=0.9-0.1)-\right.$ bearing the $(R)$ configuration of the Sergeant $[(R)-2]$ were also synthetized yielding opposite helical senses due to their enantiomeric relationship (See Figure S19).

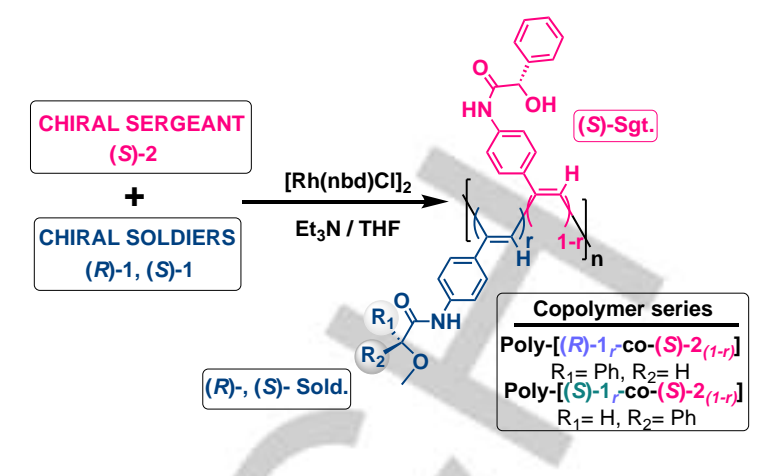

Figure 4. Monomer and copolymer structures used in this study.

NMR (vinyl protons, $\delta=5.7-5.8 \mathrm{ppm}$ ) and Raman (c.a. 1575, $1340,1004 \mathrm{~cm}^{-1}$ ) spectra indicated in all cases the presence of cis polyene backbones (see SI). ${ }^{[49-51]}$ In addition, DSC measurements showed traces typical for cis-cisoidal polyene backbones (see SI). ${ }^{[53]}$

NMR studies also indicated that chiral Soldier/chiral Sergeant monomer ratios in the copolymers were coincident with the feeding mixtures (see $\mathrm{SI}$ ). Moreover, their random distribution within the copolymer chain was demonstrated by using the KelenTüdos ${ }^{[54-55]}$ approach (see SI).

The molecular weights of the copolymers were estimated by GPC (THF as eluent with polystyrene standards as calibrants; see SI for details) to be between $\mathrm{Mn}=10000$ and 40000 with $\mathrm{Mw} / \mathrm{Mn}$ values in a 1.2-2.7 range.

Chiral-to-chiral communication mechanisms in the poly-[(S)1r-co-(S)-2(1-r)] copolymer series

CD spectra of the poly-[(S)-1 r co- $\left.(S)-\mathbf{2}_{(1-r)}\right]$ copolymer series in several solvents showed the existence of different chiral communication mechanisms between the two monomers, which depend on the individual dynamic behavior observed in the homopolymers of the two copolymer components (Figure 5 and $\mathrm{SI})$.

In this way, homopolymers poly-(S)-1 and poly-(S)-2 show in chloroform the formation of an axially racemic helix and a well folded $P$ helix respectively (Figure 5a). ${ }^{[56-58]} \mathrm{CD}$ spectra of the poly-[(S)-1 $\left.\mathbf{1}_{\mathrm{r}}-\mathrm{co}-(S)-\mathbf{2}_{(1-\mathrm{r})}\right]$ copolymer series show in this solvent the classical Sergeants and Soldiers effect, where the chiral Sergeant $[(S)-2]$ is able to induce a $P$ helix in the chiral Soldier [(S)-1] in a very effective way - just $3 \%$ of the chiral Sergeant $[(S)-2]$ is enough to induce the maximum helical preference (CD signature at the vinylic region) in the copolymer chain, $r=0.03-$ (Figure $5 b) .{ }^{[55-56]}$ From the mechanistic point of view, in chloroform this process is originated by the ap conformation of the Sergeant $[(S)$ 2] (Figure $5 b),{ }^{[48]}$ which commands the Soldier [(S)-1] to adopt an ap conformation that in turn induces the same $P$ helix orientation in the copolymer chain. The conformational composition at the pendants was determined by fixing their ap or $s p$ conformations by addition of either monovalent or divalent metal ions (see SI). ${ }^{[46-}$ 48]

In THF, homopolymers poly-(S)-1 and poly-(S)-2 show CD traces indicative of a screw sense excess towards the $P$ helices $\left[C_{380}\right.$ $(+)]$ (Figure 5a), ${ }^{[56-58]}$ although their magnitude is moderate. This fact indicates a slight screw sense excess towards a $P$ helix in both polymers. CD studies for the poly-[(S)-1 r co- $\left.(S)-\mathbf{2}_{(1-r)}\right]$ copolymer series in this solvent show that all the copolymers adopt a preferred $P$ helix, although the magnitude of the CD 
spectra is approximately twice that of the original homopolymers (Figure 5c).

This chiral enhancement effect is observed in all the poly-[(S)-1r co-(S)-2 (1-r) copolymer series, independently of the copolymer composition, which indicates that an effective chiral communication mechanism is being produced within the copolymer chain. In this way, a synergistic chiral enhancement arises due to a reciprocal stabilization of the ap conformers in both monomer repeating units -(S)-1 and (S)-2- once they are copolymerized.

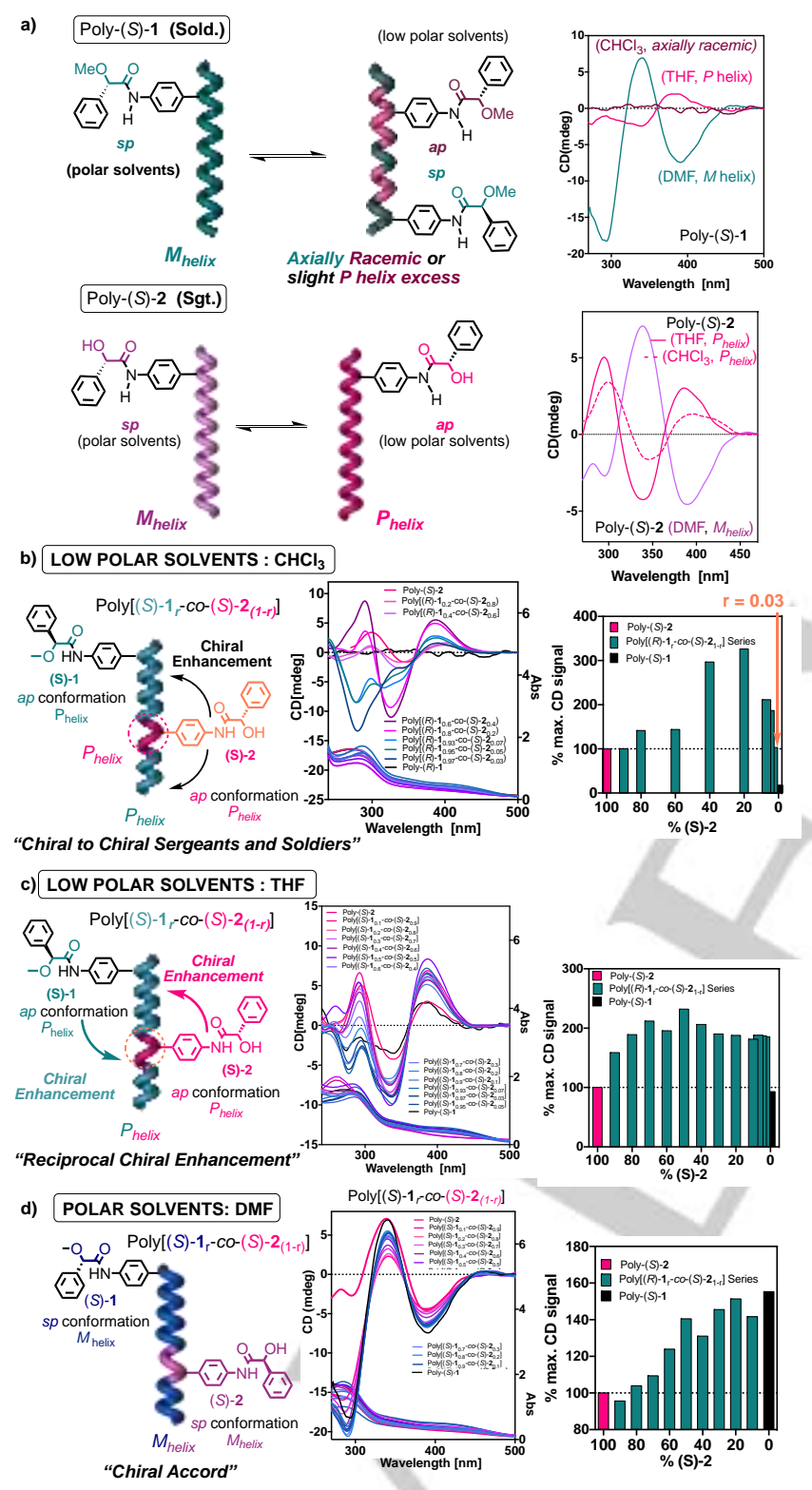

Figure 5. a) CD spectra, helical sense and major conformations at the pendants for poly-(S)-1 and poly-(S)-2 in low polar (THF and $\left.\mathrm{CHCl}_{3}\right)$ and polar solvents (DMF). CD studies of the poly-[(S)-1 $\left.-\mathrm{r}-\mathrm{CO}-(S)-\mathbf{2}_{(1-\mathrm{r})}\right]$ series in (b) low polar $\left(\mathrm{CHCl}_{3}\right)$, (c) low polar (THF) and (d) polar (DMF) solvents highlighting the conformational composition of the copolymer components. ECD and UV-Vis measurements were performed in a $1 \mathrm{~mm}$ quartz cuvette. Concentration of homopolymers and copolymers $=0.3 \mathrm{mg} / \mathrm{mL}$.
Finally, analogous studies were carried out in polar solvents such as DMF or DMSO. In these solvents, homopolymers poly-(S)-1 and poly-(S)-2 adopt helical structures with an $M$ screw sense preference. Interestingly, in this solvent the magnitude of the CD spectra is greater for poly-(S)-1 than for poly-(S)-2, which indicates better folding for the first one.

CD studies of the poly-[(S)-1 $r$ co- $\left.(S)-\mathbf{2}_{(1-r)}\right]$ copolymer series in DFM show a lack of communication between the two components of the copolymer. The CD spectra of the different copolymers along the series vary with the copolymer composition and agree with the magnitude of the parent homopolymers. This lack of communication between chiral monomers that promote the same helical sense into the copolymers is denoted as Chiral Accord. ${ }^{[59]}$ Thus, within a single chiral copolymer series, three different chiral communication mechanism are observed —Chiral-to-Chiral Sergeants and Soldiers effect, Reciprocal Chiral Enhancement and Chiral Accord-, which are activated depending on the conformational composition at the pendant groups.

\subsection{Chiral-to-chiral communication mechanisms in the poly-} $\left[(R)-1_{r}-\operatorname{co}-(S)-2_{(1-r)}\right]$ copolymer series

CD spectra of the diastereomeric poly-[(R)-1rco- $\left.(S)-\mathbf{2}_{(1-\eta)}\right]$ series showed again the existence of different chiral communication mechanisms between the two monomers in solvents with different polarity and donor ability such as $\mathrm{CHCl}_{3}$, THF or DMF (Figure 6 and $\mathrm{SI}$ ). Interestingly, the chiral communication mechanisms that arise between the two comonomers - $(R)-\mathbf{1}$ and (S)-2-depends again on their conformational composition in the corresponding homopolymers.

Thus, in chloroform, poly- $(R)-\mathbf{1}$ is formed by a mixture of $P$ or $M$ helices in an equal population due to the existence of an equilibrium between two different conformers in the pendant group (sp/ap), that induce opposite helical sense in the PPA (Figure 6a). ${ }^{[46]}$ On the other hand, poly-(S)-2 adopts in chloroform a screw sense excess towards a $P$ helix due to the presence of a preferred ap conformer at the pendant (Figure 6a). ${ }^{[8]}$

CD studies of the corresponding poly-[(R)-1, $\left.\mathbf{1}_{r}-(S)-2_{(1-n)}\right]$ series in chloroform show the activation of the Sergeants and Soldiers effect and that the chiral Sergeant $[(S)-2]$ is able to induce a $P$ helix $\left[\mathrm{CD}_{380}(+)\right]$ in the chiral Soldier $[(R)-1]$ in a very effective way $(r=0.03)$. From a mechanistic point of view, Sergeant $[(S)-2]$, which adopts a preferred ap conformation at the pendant and induces a $P$ helix on the copolymer, is able to command a $s p$ conformation on the Soldiers $[(R)-1]$ that also induce the same $P$ helix on the helix (Figure 6b).

On the other hand, in THF, homopolymers poly-( $R)-1$ and poly$(S)-2$ show CD traces indicative of screw sense excesses with opposite helicities - poly-(R)-1 $M$ helix $\left[\mathrm{CD}_{380}(-)\right]$; poly-(S)-2 $P$ helix $\left[C_{380}(+)\right]$ (Figure 6a)- The helix induction in both homopolymers, poly- $(R)-\mathbf{1}$ and poly-(S)-2, is modest, indicating a low excess of the ap conformer at the pendant group. CD studies of the poly- $\left[(R)-\mathbf{1}_{r}-\mathrm{co}-(S)-\mathbf{2}_{(1-r)}\right]$ series in this solvent reveal that different communication mechanism have been triggered depending on the monomer ratios within the copolymer chain, resulting in the magnification of the CD trace towards either a $P$ or $M$ helices (Figure $6 \mathrm{c}$ ). For instance, all the copolymers in a the poly-[(R)-1<0.3-CO-(S)-2>0.7] range adopt a helical structure with a preferred $P$ sense commanded by monomer $(S)-2$ and where the folding of the parent poly-(S)-2 can be improved in the order of $200-300 \%$ by doping it with monomer $(R)-\mathbf{1}$. On the other hand, those copolymers containing monomer $(R)-\mathbf{1}$ in a ratio higher than $90 \%$-poly- $\left[(R)-\mathbf{1}>0.9-c 0-(S)-2_{<0.1}\right]$ produce an $M$ helix 
commanded by monomer $(R) \mathbf{- 1}$, and where the folding of the parent poly- $(R)-\mathbf{1}$ can be improved in by $200 \%$ by doping it with a small amount of monomer (S)-2 (3-5\%) (Figure 6c). This fact indicates that a large chiral enhancement towards the $P$ or $M$ helical senses in THF can be activated throughout the poly- $[(R)$ $\mathbf{1}_{r}$ co- $\left.(S)-\mathbf{2}_{(1-n]}\right]$ series by playing with the monomer ratios.

Finally, CD studies of the poly-[(R)-1, $r$ co- $\left.(S)-2_{(1-n]}\right]$ series were carried out in DMF. In this solvent, the corresponding homopolymers show well-folded helical structures with opposite helical senses and similar magnitude - poly- $(R)-1 P$ helix $\left[\mathrm{CD}_{380}\right.$ (+)]; poly-(S)-2 $M$ helix [ $\left.C_{380}(-)\right]$ (Figure 6a)- This fact indicates that the conformational preferences in both homopolymers are similar and therefore also means that the strength of the two monomers within the copolymer chain should be similar.

$\mathrm{CD}$ studies of the poly-[(R)-1, $\left.\mathbf{1}_{\text {co- }}(S)-\mathbf{2}_{(1-r)}\right]$ copolymer series in DMF show the absence of chiral communication between the two monomers (Figure 6d). In this case, a Chiral Conflict emerged, ${ }^{[41]}$ where the two monomers forming the copolymer induce opposite helical senses within the copolymer chain and identical to those that they induce in the corresponding homopolymers - monomer $(R)$-1 induces a $P$ helix, while monomer $(S)-2$ induces an $M$ helix -, which shows the lack of communication between comonomers along the copolymer chain.

Therefore, we could observe again along this copolymer series poly-[(R)-1, co- $\left.(S)-\mathbf{2}_{(1-r)}\right]$-, how different chiral communication effects - Sergeants and Soldiers, Chiral Enhancement or Chiral Conflict- can be activated depending on the conformational composition at the pendant groups.

\section{Conclusion}

In conclusion, we have demonstrated that different chiral-to-chiral communication mechanisms can be activated in a copolymer by playing with the conformational composition of the two components. Thus, if one monomer shows a preferred conformation in one solvent [m- $(S)-2]$, while the other $[\mathrm{m}-(R)$ or $\mathrm{m}-(S)-1$ ] shows an equilibrium between different conformers, a Sergeants and Soldiers effect emerges and all the copolymers of the two possible copolymer series - poly- $\left[(R)-\mathbf{1}_{\mathrm{r}}-\mathrm{co}-(S)-\mathbf{2}_{(1-r)]}\right.$ or poly-[(S)-1 $\mathbf{1}_{\mathrm{r}}-\mathrm{Co}-(S)-\mathbf{2}_{(1-r)]}-$ adopt the same $P$ helical structure, independently on the absolute configuration of the Soldier [m- $(R)$ or $\mathrm{m}-(S)-1]$.

On the other hand, if the copolymer is made by monomers that do not produce well folded homopolymers, e.g., poly-1 and poly-2 in THF, copolymerization of those two monomers can result in a Reciprocal Chiral Enhancement effect. For instance, homopolymers poly-(S)-1 and poly-(S)-2 produced helical structures with poor $P$ helical sense excesses in THF, which can be increased by $200 \%$ by copolymerization of the two monomers. On the other hand, if $\mathrm{m}-(R)-\mathbf{1}$ and $\mathrm{m}-(S)-\mathbf{2}$, which induce opposite helical senses, are copolymerized, the Chiral Enhancement can be produced in both directions, either $P$ or $M$, depending on the monomer ratios within the copolymer.

Finally, it was found that if the two monomers that form the copolymer are well folded, e.g., poly-1 and poly-2 in DMF, a lack of communication between monomers is observed producing a Chiral Accord when the two components induce the same helical sense -e.g., poly-[(S)-1 $\left.\mathbf{1}_{\mathrm{r}}-\mathrm{Co}-(S)-\mathbf{2}_{(1-\mathrm{r})}\right]$, poly-(S)-1 and poly-(S)-2 $M$ helix - or a Chiral Conflict when the two components induce opposite helical senses -e.g., poly-[(R)-1 $\left.\mathbf{1}_{\mathrm{r}}-\mathrm{CO}-(S)-\mathbf{2}_{(1-\mathrm{r})}\right]$, poly- $(R)-$ $1 M$ helix and poly-(S)-2 $P$ helix-.

Therefore, it can be concluded that playing with the conformational composition of the two chiral components of a copolymer series, it is possible to activate/deactivate different chiral communication effects along polymer chains, which will allow us to enhance or decrease their folding at our convenience and depending on the potential application sought for the material.

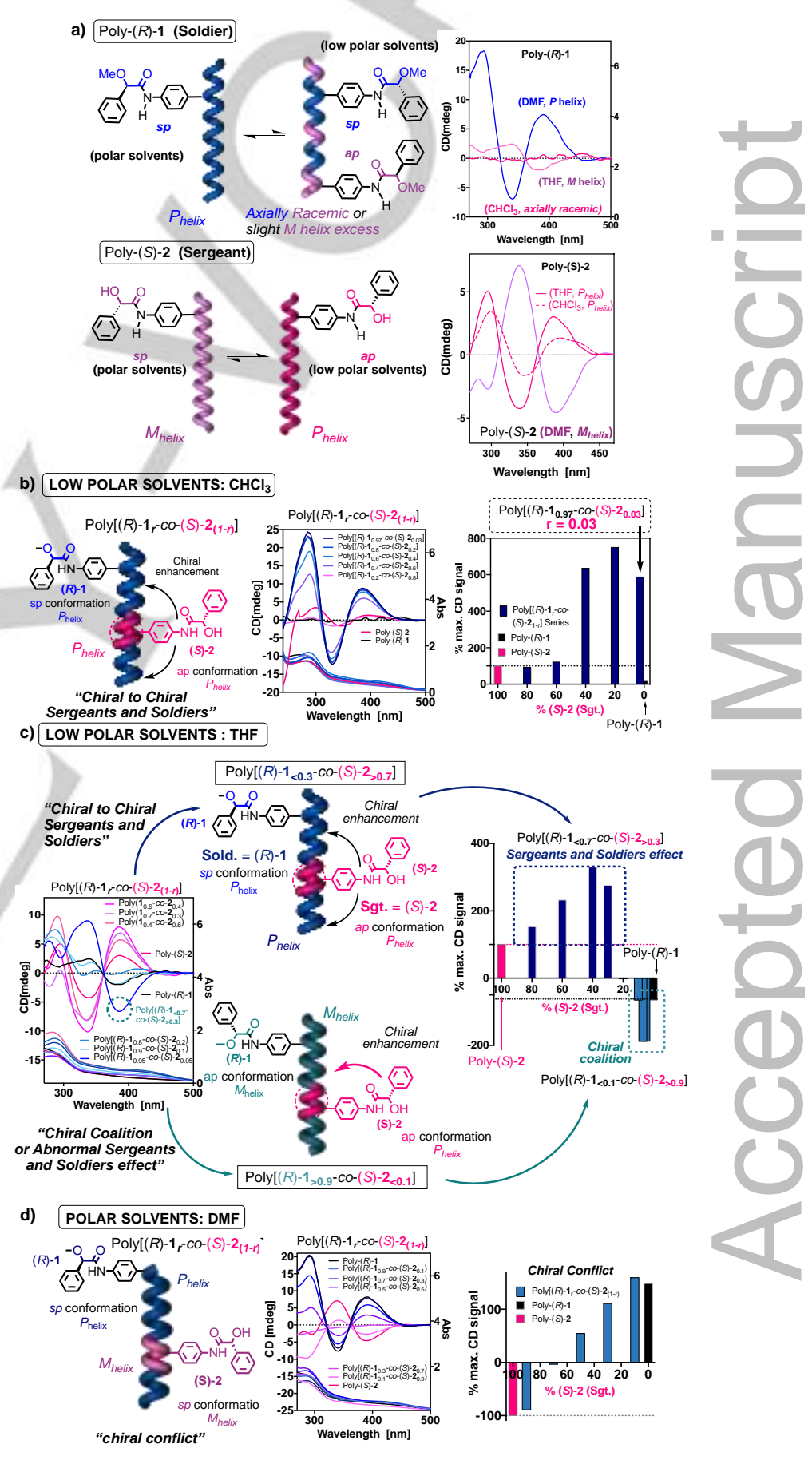

Figure 6. a) CD spectra, helical sense and major conformations at the pendants for poly-(R)-1 and poly-(S)-2 in low polar (THF and $\mathrm{CHCl}_{3}$ ) and polar solvents (DMF). CD studies of the poly-[(R)-1 $\left.\mathbf{1}_{\mathrm{r}}-\mathrm{CO}-(S)-\mathbf{2}_{(1-\mathrm{r})}\right]$ series in (b) low polar $\left(\mathrm{CHCl}_{3}\right)$, (c) low polar (THF) and (d) polar (DMF) solvents highlighting the conformational composition of the copolymer components. ECD and UV-Vis measurements 
were performed in a $1 \mathrm{~mm}$ quartz cuvette. Concentration of homopolymers and copolymers $=0.3 \mathrm{mg} / \mathrm{mL}$.

\section{Acknowledgements}

Financial support from MINECO (CTQ2015-70519-P), Xunta de Galicia (ED431C 2018/30, Centro singular de investigación de Galicia accreditation 2019-2022, ED431G 2019/03, and postdoctoral fellowship to R. R.) and the European Union (European Regional Development Fund - ERDF) is gratefully acknowledged. $\ddagger \mathrm{K}$. Cobos and R. Rodríguez contributed equally to this work.

Keywords: Chiral Communication - Poly(phenylacetylene) • Sergeants and Soldiers $\bullet$ Chiral Coalition $\bullet$ Chiral Conflict

[1] [1] A. Xu, T. Masuda, A. Zhang, Polym. Rev. 2017, 57, 138-158.

[2] E. Yashima, N. Ousaka, D. Taura, K. Shimomura, T. Ikai, K. Maeda, Chem. Rev. 2016, 116, 13752-13990

[3] F. Freire, E. Quiñoá, R. Riguera, Chem. Rev. 2016, 116, 1242-1271.

[4] E. Yashima, K. Maeda, H. Lida, Y. Furusho, K. Nagai, Chem. Rev. 2009, 109, 6102-6211.

[5] J. Liu, J. W. Y. Lam, B. Z. Tang, Chem. Rev. 2009, 109, 5799-5867.

[6] E. Yashima, K. Maeda, Y. Furusho, Acc. Chem. Res. 2008, 41, 11661180.

[7] J. G. Rudick, V. Percec, Acc. Chem. Res. 2008, 41, 1641-1652

[8] E. Yashima, K. Maeda, Macromolecules, 2008, 41, 3-12.

[9] E. Yashima, K. Maeda, Helically in Foldamers: structure, properties, and applications, (Eds: Hecht, S.; Huc, I). Wiley-VCH, Weinheim, Germany 2007, Ch. 11.

[10] K. Maeda, E. Yashima, Top. Curr. Chem. 2006, 265, 47-88.

[11] R. Ishidate, A. J. Markvoort, K. Maeda, E. Yashima, J. Am. Chem. Soc. 2019,141, 7605-7614.

[12] T. Ikai, R. Ishidate, K. Inoue, K. Kaygisiz, K. Maeda, E. Yashima, Macromolecules 2020, 53, 973-981

[13] S. Leiras, F. Freire, J. M. Seco, E. Quiñoá, R. Riguera, Chem. Sci. 2013, 4, 2735-2743.

[14] E. Yashima, K. Maeda, O. Sato, J. Am. Chem Soc., 2001, 123, 81598160.

[15] R. Rodríguez, E. Quiñoá, R. Riguera, F. Freire, Chem. Mater. 2018, 30, 2493-2497.

[16] E. Suárez-Picado, E. Quiñoá, R. Riguera, F. Freire, Chem. Mater. 2018, 30, 6908-6914.

[17] E. Suárez-Picado, E. Quiñoá, R. Riguera, F. Freire, Angew. Chem. Int. Ed., 2020, 59, 4537-4543

[18] R. Rodríguez, E. Suárez-Picado, E. Quiñoá, R. Riguera, F. Freire, Angew. Chem. Int. Ed., 2020, 59, 8616-8622.

[19] R. Rodríguez, E. Quiñoá, R. Riguera, F. Freire, Small, 2019, 15, 1970070.

[20] M. Fukuda, R. Rodríguez, Z. Fernández, T. Nishimura, D. Hirose, G. Watanabe, E. Quiñoá, F. Freire, Chem. Commun., 2019, 55, 7906-7909

[21] M. M. Green, J. W. Park, T. Sato, A. Teramoto, S. Lifson, R. L. Selinger, J. V. Selinger, Angew. Chem., Int. Ed. 1999, 38, 3138-3154.

[22] H. Gu, Y. Nakamura, T. Sato, A. Teramoto, M. M. Green, S. K. Jha, C. Andreola, M. P. Reidy, Macromolecules 1998, 31, 6362-6368.

[23] M. M. Green, N. C. Peterson, T. Sato, A. Teramoto, R. Cook, S. A. Lifson, Science 1995, 268, 1860-1866.

[24] M. M, Green, M. P. Reidy, R. D. Johnson, G. Darling, D. J. O'Leary, G. Willson, J. Am. Chem. Soc. 1989, 111, 6452-6454.

[25] Y. Liu, Ch. Chen, T. Wang, M. Liu, Langmuir 2016, 32, 322-328.

[26] V. Jain, K.-S. Cheon, K. Tang, S. Jha, M. M. Green, Isr. J. Chem. 2011, 51, 1067-1074.

[27] S. Arias, J. Bergueiro, F. Freire, E. Quiñoá, R. Riguera, Small, 2016, 12 , 238-244.

[28] Y. Nagata, T. Nishikawa, M. Suginome, ACS Macro Lett., 2016, 5, 519522.
[29] Y. Nagata, T. Nishikawa, M. Suginome, J. Am. Chem. Soc., 2015, 137, 4070-4073.

[30] J. Bergueiro, F. Freire, E. P. Wendler, J. M. Seco, E. Quiñoá, R. Riguera, Chem. Sci. 2014, 5, 2170-2176.

[31] Z. Yan, S. Cai, Y. Tan, J. Zhang, C. Yan, T. Xu, X. Wan, ACS Macro Lett. 2019, 8, 789-794.

[32] M. A. Mateos-Timoneda, M. Crego-Calama, D. N. Reinhoud, Chem. Soc. Rev., 2004, 33, 363-372

[33] H. lida, M. Miki, S. Iwahana, E. Yashima, Chem. Eur. J. 2014, 20, 42574262.

[34] R. Rodríguez, E. Quiñoá, R. Riguera, F. Freire, Chem. Mater. 2018, 30, 2493-2497.

[35] K. Shimomura, T. Ikai, S. Kanoh, E. Yashima, K. Maeda, Nat. Chem. 2014, 6, 429-434.

[36] D. Hirose, A. Isobe, E. Quiñoá, F. Freire, K. Maeda. J. Am. Chem. Soc 2019, 141, 8592-8598.

[37] H. lida, Z. Tang, E. Yashima, J. Polym. Sci., Part A: Polym. Chem. 2013 51, 2869-2879.

[38] Z. Tang, H. lida, H.-Y. Hu, E. Yashima, ACS Macro Lett. 2012, 1, 261265.

[39] K. Cobos, E. Quiñoá, R. Riguera, F. Freire, J. Am. Chem. Soc. 2018, 140, 12239-12246.

[40] S. Arias, R. Rodríguez, E. Quiñoá, R. Riguera, F. Freire, J. Am. Chem. Soc. 2018, 140, 667-674

[41] M. Alzubi, S. Arias, R. Rodríguez, E. Quiñoá, R. Riguera, F. Freire Angew. Chem. Int. Ed. 2019, 58, 13365-13369

[42] R. Rodríguez, S. Arias, E. Quiñoá, R. Riguera, F. Freire, Nanoscale, 2017, 9, 17752-17757.

[43] S. Arias, F. Freire, E. Quiñoá, R. Riguera, Polym. Chem. 2015, 6, 4725 4733.

[44] S. Arias, F. Freire, E. Quiñoá, R. Riguera, Angew. Chem., Int. Ed. 2014 53, 13720-13724.

[45] F. Freire, J. M. Seco, E. Quiñoá, R. Riguera, J. Am. Chem. Soc. 2012 134, 19374-19383.

[46] F. Freire, J. M. Seco, E. Quiñoá, R. Riguera, Angew. Chem., Int. Ed. 2011, 50, 11692-11696

[47] J. Bergueiro, M. Núñez-Martínez, E. Quiñoá, R. Riguera, F. Freire, Nanoscale Horiz., 2020, 5, 495-500.

[48] K. Cobos, R. Rodríguez, O. Domarco, E. Quiñoá, R. Riguera, F. Freire, Macromolecules, 2020, 53, 3182-3193.

[49] K. K. L. Cheuk, B. S. Li, J. W. Y. Lam, Y. Xie, B. Z. Tang, Macromolecules, 2008, 41, 5997-6005.

[50] M. G. Mayershofer, O. Nuyken, J. Polym. Sci., Part A: Polym. Chem., 2005, 43, 5723-5747.

[51] B. S. Li, K. K. L. Cheuk, L. Ling, J. X. X. Chen, C. Baiand, B. Z. Tang Macromolecules, 2003, 36, 77-85.

[52] K. K. L. Cheuk, J. W. Y. Lam, L. M. Lai, Y. Dongand, B. Z. Tang, Macromolecules, 2003, 36, 9752.

[53] L. Liu, T. Namikoshi, Y. Zang, T. Aoki, S. Hadano, Y. Abe, I. Wasuzu, T. Tsutsuba, M. Teraguchi, T. Kaneko, J. Am. Chem. Soc. 2013, 135, 602605.

[54] K. Maeda, M. Muto, T. Sato, E. Yashima, Macromolecules, 2011, 44 8343-8349.

[55] T. Kelen, F. Tüdös, J. Macromol. Sci. Chem., 1975, 9, 1-27.

[56] B. Fernández, R. Rodríguez, A. Rizzo, E. Quiñoá, R. Riguera, F. Freire Angew. Chem., Int. Ed. 2018, 57, 3666

[57] B. Fernández, R. Rodríguez, E. Quiñoá, R. Riguera, F. Freire, ACS Omega, 2019, 4, 5233-5240.

[58] L. Palomo, R. Rodríguez, S. Medina, E. Quiñoá, J. Casado, F. Freire, F. J: Ramírez, Angew. Chem. Int. Ed., 2020, 59, 9080-9087.

[59] S. Sforza, T. Tedeschi, R. Corradini, R. Marcheli, Eur. J. Org. Chem. 2007, 5879-5885. 


\section{WILEY-VCH}

\section{RESEARCH ARTICLE}

\section{Entry for the Table of Contents}

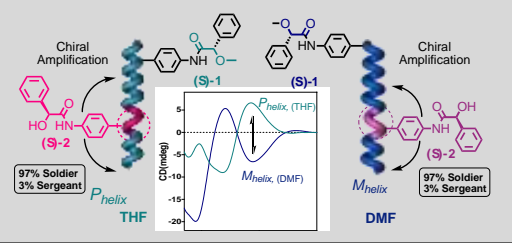

A complete set of Communication Mechanisms - Chiral-to-Chiral Sergeants and Soldiers effect, Chiral Coalition, Chiral Conflict, Chiral Accord and also a synergistic chiral enhancement effect - can be activated in a chiral copolymer by acting on the conformational composition and the absolute configuration of the components.

Institute and/or researcher Twitter usernames: @ciqususc, @felixfreirelab 